\title{
Caveolins: targeting pro-survival signaling in the heart and brain
}

\author{
Creed M. Stary ${ }^{1+}$, Yasuo M. Tsutsumi ${ }^{2+}$, Piyush M. Patel ${ }^{1}$, Brian P. Head ${ }^{1}$, Hemal H. Patel ${ }^{1}$ and \\ David M. Roth ${ }^{1 *}$
}

1 Department of Anesthesiology, Veterans Affairs San Diego Healthcare System, University of California, San Diego, La Jolla, CA, USA

${ }^{2}$ Department of Anesthesiology, The University of Tokushima, Tokushima, Japan

\section{Edited by:}

Elisabeth Lambert, BakerIDI Heart and Diabetes Institute, Australia

Reviewed by:

Emmanuel M. Awumey, North

Carolina Central University, USA

Garrett Gross, Medical College

of Wisconsin, USA

*Correspondence:

David M. Roth, Department of Anesthesiology, Veterans Affairs San Diego Health Care System, University of California, San Diego, 200 W. Arbor Drive, San Diego,

CA 92103-8770, USA.

e-mail:droth@ucsd.edu

${ }^{t}$ These authors equally contributed to this review and should be considered primary authors.
The present review discusses intracellular signaling moieties specific to membrane lipid rafts (MLRs) and the scaffolding proteins caveolin and introduces current data promoting their potential role in the treatment of pathologies of the heart and brain. MLRs are discreet microdomains of the plasma membrane enriched in gylcosphingolipids and cholesterol that concentrate and localize signaling molecules. Caveolin proteins are necessary for the formation of MLRs, and are responsible for coordinating signaling events by scaffolding and enriching numerous signaling moieties in close proximity. Specifically in the heart and brain, caveolins are necessary for the cytoprotective phenomenon termed ischemic and anesthetic preconditioning. Targeted overexpression of caveolin in the heart and brain leads to induction of multiple pro-survival and pro-growth signaling pathways; thus, caveolins represent a potential novel therapeutic target for cardiac and neurological pathologies.

Keywords: Cav-1, Cav-3, membrane lipid raft, MLR, caveolae, neurogenesis, preconditioning

\section{INTRODUCTION}

Cardiac (i.e., ischemic heart disease, cardiomyopathy, congestive heart failure) and neuronal (i.e., stroke, traumatic brain injury, neurodegenerative disorders) diseases together represent a majority of mortalities (Hoyert, 2012) and sources of disability (Soni, 2011) in the United States and the developed and developing world. In survivors, these diseases are collectively associated with a high rate of rehabilitation and institutionalization, which translates to a significant cost and resource burden on the healthcare system (Soni, 2011). To date, clinical trials investigating pharmacologic therapies targeted at pro-survival pathways in the heart and brain have been largely ineffective in enhancing recovery and improving clinical outcome (Marler, 2007; Rose et al., 2010). This may be due to a limited ability to regulate pro-survival signaling that can occur in these organ systems following injury (Hicks et al., 1998; Biegon et al., 2004; Atkins et al., 2007, 2009; Rose et al., 2010). This review will highlight recent studies demonstrating that targeted augmentation of the subcellular microdomains that coordinate the trafficking and localization of signaling events restores multiple pro-survival and pro-growth signaling pathways specifically in the heart and brain, which may provide a new therapeutic avenue for treating a number of disease states affecting these organ systems.

\section{MEMBRANE LIPID RAFTS, CAVEOLAE, AND CAVEOLINS}

Membrane lipid rafts (MLRs) are discreet microdomains of the cell membrane that concentrate and localize signaling molecules by providing a stable platform for protein anchoring. Stability of protein anchoring is afforded by the lipid composition of
MLRs, which are rich in sphingomyelin, glycosphingolipids, and cholesterol. By promoting a favorable binding environment for cell signaling receptors and their downstream effectors, MLRs promote a variety of physiological functions such as cell surface signaling (Lisanti et al., 1994; Ostrom et al., 2001; Steinberg and Brunton, 2001; Ostrom, 2002; Williams and Lisanti, 2004), endocytosis (Anderson, 1993), calcium homeostasis (Fujimoto et al., 1992; Fujimoto, 1993; Scriven et al., 2002) and intracellular cholesterol transport (Murata et al., 1995; Smart et al., 1996). Caveolae (Figure 1A), morphologic invaginations of the cell surface, are subsets of MLRs containing sphingolipids and cholesterol (Figure 1B) that were first observed in 1953 by Palade (1953), but their role in cell-surface signaling has only been realized in the past two decades. By regulating the intracellular trafficking and delivery of cholesterol to the cell membrane, caveolar formation and stabilization is dependent on the key structural protein, caveolin (Smart et al., 1999).

Caveolins (Figure 1C) are a family of proteins approximately $17-24 \mathrm{kDa}$ in size that exist in three isoforms (Cav-1, -2, and -3), all containing an invariant hydrophobic central domain that promotes insertion in lipid bilayers in a hairpin loop manner, with both the $\mathrm{COOH}$ and $\mathrm{NH}_{2}$ termini facing the cytoplasm (Dupree et al., 1993; Dietzen et al., 1995; Monier et al., 1995; Tang et al., 1996). Initial gene knockout (KO) studies provided evidence that Cav-1 is essential for formation of caveolae in endothelial cells, fibroblasts, and pneumocytes (Razani et al., 2001), whereas Cav-2 plays an unclear but likely supportive role by forming hetero-oligomers with Cav-1 (Monier et al., 1995; Razani et al., 2001). Cav-3 KO mice are viable but subject to skeletal and 
A

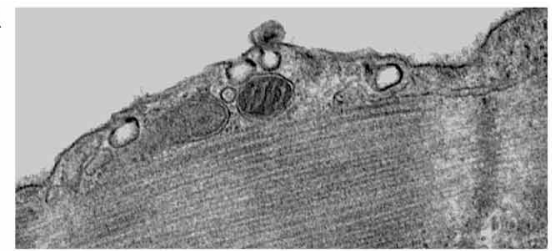

B

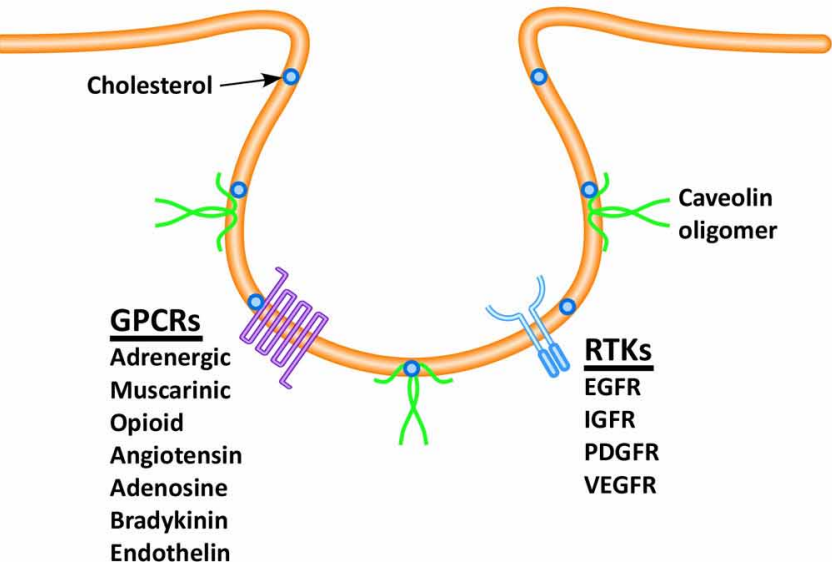

C

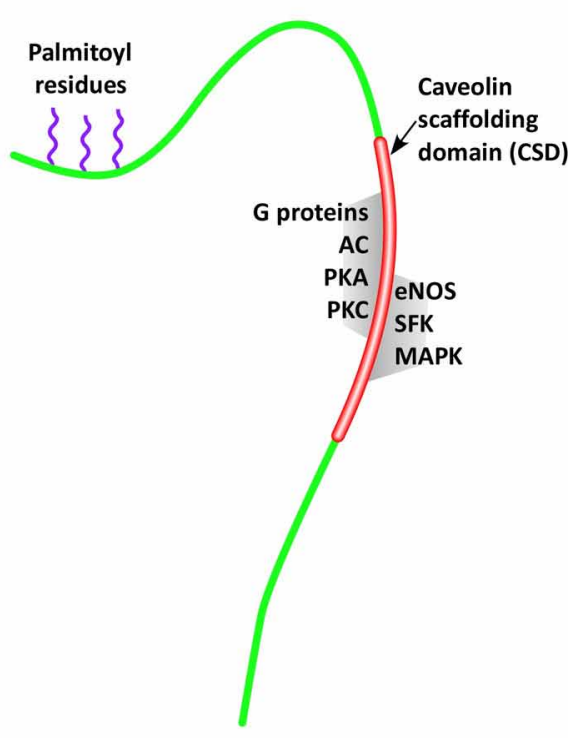

FIGURE 1 | Caveolae are invaginations of the cell membrane readily visualized via electron microscopy $(A)$, which play a critical role in pro-survival and pro-growth signaling. The formation and stabilization of caveolae depend on the presence of cholesterol and the structural protein caveolin, and serve to spatially localize signaling receptors (B), including receptor tyrosine kinases (RTKs) and G-protein coupled receptors (GPCRs). Caveolin monomers (C), contains a palmitic acid anchor that serves to stabilize the protein within the cell membrane, and a scaffolding domain, which is the binding site for many pro-survival and pro-growth molecules. (Definitions: EGFR, epidermal growth factor receptor; IGFR, insulin growth factor receptor; PDGFR, platelet derived growth factor receptor; VEGFR, vascular endothelial growth factor receptor; AC, adenylyl cyclase; PKA, protein kinase A; PKC, protein kinase $\mathrm{C}$; eNOS, endothelial nitric oxide synthase; SFK, Src family kinases; MAPK, mitogen activated protein kinases). cardiac myopathies (Hagiwara et al., 2000; Galbiati et al., 2001), belying a critical role for Cav-3 in muscle (Tang et al., 1996; Galbiati et al., 1998). However, all three caveolin isoforms have been subsequently demonstrated in the central nervous system (CNS) (Zschocke et al., 2002; Shin et al., 2005), suggesting a greater degree of tissue ubiquity for Cav-3, despite early indications of specificity to muscle. Similarly, Cav-1 expression has subsequently been demonstrated in both atrial (Volonte et al., 2008) and ventricular myocytes (Cho et al., 2010). Caveolins are also present in non-caveolar rafts, which exist as planar, transient membrane microdomains, where they are complexed with glycophosphatidylinositol-anchored signaling proteins (Boscher and Nabi, 2012), implying a spatial role in cell-surface and intracellular signaling cascades. In fact all three caveolin isoforms contain a conserved "caveolin scaffolding domain" (CSD, Figure 1C), which functions as the physical binding site for a number of signaling molecules.

\section{CAVEOLINS COORDINATE MULTIPLE SIGNALING PATHWAYS IN THE HEART}

A number of signaling molecules localize to the MLR by aggregating with the CSD on the C-terminal end of the caveolin protein (Figure 1C). G-protein coupled receptors (GPCRs) comprise a large superfamily of transmembrane signaling receptors that transduce extracellular molecules (e.g., endothelin, bradykinin, serotonin, angiotensin-1, opioid, adenosine, and adrenergic) to intracellular signals. It has been proposed that compartmentalization of these receptors and other proteins in plasma membrane microdomains may promote and regulate intracellular signaling (Ostrom, 2002; Ostrom et al., 2002; Insel et al., 2005). Evidence to support the interaction between GPCRs within MLRs came from observations that the $\beta 2$ adrenergic receptor localized to lipid-rich buoyant fractions and within caveolae (Ostrom et al., 2000; Rybin et al., 2000). Compartmentalization of signaling was further suggested by experiments demonstrating that the inactive $\mathrm{G} \alpha$ subunit may concentrate in caveolae and associate with the CSD (Oh and Schnitzer, 2001), while activation of the subunit causes $\mathrm{G} \alpha$ to dissociate and remain separate from caveolae (Li et al., 1995). Moreover, endocytosis of ligand-bound GPCRs occurs via a caveolae-dependent mechanism, which in turn initiates or terminates signaling (Escriche et al., 2003; Rapacciuolo et al., 2003).

Endothelial nitric oxide synthase (eNOS) is involved in the control of many important functions, such as angiogenesis, vasorelaxation, and permeability. Mice deficient in Cav-1 display increased nitric oxide $(\mathrm{NO})$ production from increased eNOS 
activity (Razani et al., 2001) with resultant increased vascular permeability in mouse lung endothelium (El-Yazbi et al., 2006), both of which are reversed by injection of a truncated Cav-1 peptide containing the CSD. Inhibition of eNOS by caveolin occurs within the systemic vascular endothelium, whereby eNOS activity does not respond to regulatory signals, NO levels remain increased, and basal cGMP levels remain elevated in rings of aorta from Cav-1 deficient mice (Drab et al., 2001; Razani et al., 2001). A role for Cav-1 as a direct negative regulator of eNOS has been demonstrated whereby application of peptide containing the caveolin CSD in vivo resulted in selective inhibition of NO (Bucci et al., 2000). However, an obligatory role for caveolin on eNOS function has also been demonstrated, whereby depletion of cholesterol resulted in disruption of agonist-stimulated NO release in endothelial cells (Blair et al., 1999). While a role for Cav-1 in endothelial NO production is evident, Cav-3 likely also plays a critical role in NO signaling in skeletal and cardiac tissue. Feron et al. (1996) first demonstrated a tissue-specific differential pattern of caveolin/eNOS co-localization, whereby eNOS was observed to complex with Cav-1 in endothelial cells, but with Cav-3 in cardiac myocytes, while Segal et al. (1999) demonstrated co-localization of Cav-3 and neuronal NOS (nNOS) in skeletal muscle. Application of oligonucleotide coding for the Cav-3 CSD to permeabilized cardiomyocytes specifically inhibited a cholinergic-mediated decrease in myocyte chronotropy and blunted elevations in cGMP, demonstrating modulation of cardiac myocyte function via the interaction of Cav-1 and eNOS (Feron et al., 1998). Global overexpression of Cav-3 was subsequently shown to result in severe cardiomyopathy and muscular dystrophy accompanied by downregulation of NOS (Aravamudan et al., 2003). Modulation of cardiac and skeletal muscle angiogenesis and vasoreactivity by the interaction of Cav3 and NOS may in part explain the phenotype of Cav-3 deficient mice, which also includes both skeletal and cardiac myopathies (Galbiati et al., 2001).

Another fundamental regulator of cell growth and differentiation is protein phosphorylation via intracellular kinases, downstream effectors of cell surface receptor binding. Phosphatidylinositol 3-kinase (PI3K) can be activated by GPCRs or tyrosine kinase receptors, and is intimately involved in cell growth and survival through activation of the anti-apoptotic Akt pathway. In cultured skeletal myocytes, disruption of MLR's impairs cell survival via inhibition of PI3K/Akt (Smythe and Rando, 2006). Furthermore, PI3K regulates insulin signaling, whereby caveolin depletion alters insulin resistance in skeletal muscle and adipose tissue (Cohen et al., 2003). Mitogenactivated protein kinases (MAPK) represent another class of protein kinases that regulate cell proliferation (Rose et al., 2010). Increased MAPK activity downregulates Cav-1 mRNA and protein levels, and overexpression of Cav-1 inhibits the MAPK signaling pathways, an inhibition that is dependent on the CSD (Engelman et al., 1998). Finally, tyrosine kinases are thought to localize to MLRs and to interact with Cav-1 (Li et al., 1996). Phosphorylation of Cav-1 occurs via the non-receptor tyrosine kinase Src (Volonte et al., 2001), which can induce muscle degeneration and inflammatory gene expression if Cav-1 expression and localization is disrupted (Smythe and Rando,
2006), but which has been implicated in myocardial protection from ischemia/reperfusion (IR) injury (Patel et al., 2007). Moreover, vascular endothelial growth factor receptor has been reported to interact with Cav-1, and initiation of angiogenesis via tyrosine kinase activation is dependent on the presence of Cav-1, underlying a significant role for caveolin in the regulation of cell growth and survival (Feng et al., 1999; Labrecque et al., 2003).

\section{CAVEOLIN-3 REGULATES CARDIAC HYPERTROPHY}

Stress on the heart produces pathogenic cell growth, whereby hemodynamic overload induces an initial hypertrophic response modulated by several signaling pathways that affect gene expression, apoptosis, inflammation, and growth factor signaling but which ultimately ends in ventricular dilation and failure (Rohini et al., 2010). Genetic deletion of Cav-1 results in a progressive biventricular cardiomyopathy, with sustained activation of MAPK, Akt and eNOS, and diminished ATP content in the heart (Cohen et al., 2003). A recent study by Cruz et al. (2012) suggested that elevated pulmonary pressures in Cav-1 deficient mice contributed to eNOS uncoupling, whereby chronic hypoxia lead to right ventricular hypertrophy, while endothelial-specific upregulation of Cav-1 ablated these changes. Given that the expression of Cav-1 is required for caveolar formation in non-muscle cells, and caveolin-3 drives caveolae formation in cardiac and skeletal muscle, a Cav-1/3 double KO mouse was generated by Park et al. (2002) in order to investigate phenotypic cardiac changes in mice completely lacking morphologic caveolae. Cav-1/3 double $\mathrm{KO}$ mice displayed a severe cardiomyopathy, with a dramatic increase in left ventricular (LV) wall thickness, decreased LV fractional shortening, disorganized, and degenerated cardiomyocyte ultrastructure, chronic interstitial fibrosis and inflammation, and augmentation of ANP expression as compared with Cav-1-KO, Cav-3 KO, and wild-type mice (Park et al., 2002). While genetic deletion of caveolin results in hypertrophy, global overexpression of Cav-3 also results in a cardiomyopathic phenotype characterized by degeneration and fibrosis (Aravamudan et al., 2003), and as well as dystrophic skeletal muscle phenotype (Galbiati et al., 2000). In contrast, Koga et al. (2003) demonstrated that adenovirus-mediated overexpression of Cav-3 in isolated cardiomyocytes provided protection from phenylephrine-induced hypertrophy, suggesting that modulation of Cav-3 specifically in cardiac myocytes may provide cardioprotection against dynamic overload. Additionally, natriuretic peptides that can modulate cardiac hypertrophy by regulating the adaptive response of the heart to hemodynamic overload via diuretic, natriuretic and vasodilatory action, are associated with caveolae and Cav-3 (Newman et al., 1991; Doyle et al., 1997). Subsequently, we demonstrated that adenovirus-mediated overexpression of Cav-3 in cardiomyocytes augments natriuretic peptide expression and Akt phosphorylation, which was blocked by PI3K inhibition and caveolar disruption (Horikawa et al., 2011). Given the potential for Cav-3 to modulate cardiac hypertrophy, we next tested whether targeting Cav-3 specifically to cardiac myocytes in vivo would alter natriuretic peptide and Akt signaling and attenuate the development of cardiac hypertrophy induced by hemodynamic overload. We developed a cardiac-targeted ( $\alpha$-myosin heavy chain promoter) Cav-3 overexpression system that caused 
a greater than twofold increase in Cav-3 specifically in cardiac myocytes and subjected the mice to transverse aortic constriction (TAC) for 1 month, to induce cardiac hypertrophy. Mice with cardiac-specific overexpression of Cav-3 exhibited augmentation of natriuretic peptide expression and nuclear Akt phosphorylation, resulting in reduced cardiac hypertrophy following TAC, with improved cardiac function and increased survival suggesting a potential therapeutic role for Cav-3 in heart failure (Horikawa et al., 2011).

\section{CAVEOLIN-3 REGULATES CARDIAC ION CHANNELS IN THE HEART}

In addition to potential therapeutic modalities targeting the mitogenic functions of caveolin, recent evidence suggests that Cav-3 expression is a critical element in modulation of membrane potential via direct interaction with ion channels (O'Connell et al., 2004; Balijepalli et al., 2006; Maguy et al., 2006; Balijepalli and Kamp, 2008; Balse et al., 2012). In the cardiac myocyte, it is established that one mechanism for $\mathrm{Ca}^{2+}$ influx occurs via opening of voltage-gated $\mathrm{Na}^{+}$channels which initiates depolarization through the cardiac sarcolemma, inducing activation of voltage-gated L-type $\mathrm{Ca}^{2+}$ channels (LCC), resulting in $\mathrm{Ca}^{2+}$ influx into the cytosol and subsequent contraction. However, current evidence suggest a more complicated system of basal oscillating "sparks" and "puffs" of cytosolic $\mathrm{Ca}^{2+}$ mediated by ligand-gated receptors (Cheng and Lederer, 2008) and contraction-independent LCCs (Makarewich et al., 2012). Dysregulated $\mathrm{Ca}^{2+}$-flux through LCC is thought to play a role in the development of cardiac hypertrophy, and early evidence suggests flux through LCC in Cav-3 rich microdoamins as a locus for this pathologic growth via the calcineurin-nuclear factor of activated T-cell signaling cascade (Makarewich et al., 2012). Cav-3 also is involved in the protein kinase A-dependent stimulation of T-type $\mathrm{Ca}^{2+}$ channels, which are re-expressed in the adult heart during hypertrophy and associated with cardiac dysfunction in heart failure (Markandeya et al., 2011). A recent study by Guo et al. (2011) suggests that Cav-3 may modulate cardiac hypertrophy and contractility via the GPCR subunit Gaq, which is responsible for activation of phospholipase C-mediated $\mathrm{Ca}^{2+}$ flux in the cardiomyocyte. Moreover, Cav-3 appears necessary to modulate adrenergic activation of protein kinase A and phosphorylation of phospholambam-independently of LCC in ventricular myocytes (Macdougall et al., 2012). Caveolae appear to contribute to regulation of excitation-contraction cycling through modulation of both $\mathrm{Ca}^{2+}$ (Lohn et al., 2000; Bergdahl et al., 2003; Kwiatek et al., 2006; Besse et al., 2011) and $\mathrm{K}^{+}$flux (Martens et al., 2001; Wang et al., 2005). Voltage-gated $\mathrm{K}^{+}$channel localizes to caveolae (Martens et al., 2001), while depletion of cholesterol impairs maintenance of intracellular $\left(\mathrm{K}^{+}\right)$, leading to destabilization of membrane polarization (Fagan et al., 2000). Conduction of depolarization throughout the heart also appears dependent on caveolins, as Cav-3 KO animals display disorganization of the T-tubule complex (Galbiati et al., 2001), and mutations in the Cav-3 gene have been identified in patients with congenital longQT syndrome (Vatta et al., 2006). Modulation of caveolin levels specifically in the heart therefore represents a potential mechanism to restore the loss in contractility and/or rhythmicity that occurs in pathogenic remodeling states such as congestive heart failure.

\section{CAVEOLIN-3 PROTECTS THE HEART FROM ISCHEMIA/REPERFUSION INJURY}

Caveolins have been shown to play a fundamental role in the phenomenon of myocardial preconditioning, whereby an initial priming stimulus confers cytoprotection to a subsequent bout of IR. Historically, the first preconditioning stimulus described in 1986 by Murry et al. (1986) was a short period of sub-lethal ischemia which they termed ischemic preconditioning (IPC). Subsequently both opioids (Schultz et al., 1997) and volatile anesthetic agents (Cason et al., 1997; Kersten et al., 1997), as well as other pharmacologic agents that activate GPCRs, were shown to confer a similar protective advantage. Preconditioning occurs in a biphasic pattern: an early phase, which occurs within minutes of the conditioning stimulus via post-translational modification of pre-existing proteins, and lasts $1-2 \mathrm{~h}$, and a delayed phase occurring $12-24 \mathrm{~h}$ afterwards mediated by de novo synthesis of pro-survival signaling components (Tonkovic-Capin et al., 2002). Many of the signaling mediators involved in cardiac protection including the $\mathrm{G} \alpha$ subunit of heterotrimeric G-proteins, Src kinases, PI3K, eNOS, MAPK, and the end-effector of IPC/APC, the $\mathrm{K}_{A T P}$ channel, are known to localize to MLRs (Krajewska and Maslowska, 2004). An early observation made by our laboratory was that IPC and APC induce alterations in the sarcolemmal membrane ultrastructure of the myocyte, increasing the number of caveolae (Patel et al., 2006, 2007), and that the intrinsic ability of rat cardiomyocytes to undergo opiod-induced preconditioning depended on the presence of caveolae and localization of the $\delta$-opiod receptor with Cav-3 (Patel et al., 2006). In followup studies, we utilized both in vitro and in vivo models to demonstrate that early-phase APC operated via a Src-dependent manner, whereby depletion of caveolae, deficiency of Cav-1 or inhibition of Src resulted in abolishment of the cytoprotective effects of the early-phase of isoflurane-induced preconditioning (Patel et al., 2007). Additionally, we observed a decreased number of myocardial caveolae in Cav-3 deficient mice, and that such mice cannot be "preconditioned" by IPC or APC (Horikawa et al., 2008; Tsutsumi et al., 2008). Given these findings, we tested the hypothesis that cardiac-specific overexpression of Cav-3 would increase caveolae, and induce an innate level of cardiac protection similar to IPC. Adenovirus-mediated Cav-3 overexpression in cardiomyocytes increased caveolar formation and induction of IPC-mediated pro-survival kinases (Tsutsumi et al., 2008). In vivo studies supported these findings: transgenic mice with cardiac-specific ( $\alpha$-myosin heavy chain promoter) Cav-3 overexpression demonstrated increased myocardial caveolar formation, augmentation of pro-survival kinases, and exhibited innate cardioprotection with improved cardiac function at a level similar to that achieved through IPC (Tsutsumi et al., 2008).

While early-phase preconditioning appears to involve the phosphorylation of preexisting proteins, delayed APC induces gene and protein expression changes that ultimately lead to the induction of various mediators, including induction of NOS (Chiari et al., 2005) and synthesis of glucose-transporter 4 (Glut-4, Nishino et al., 2004). While a clear role for Cav-1 and 
Cav-3 exists in the induction of the early-phase of preconditioing, we sought to investigate whether either caveolin isoform contributed to the regulation of protein expression during the delayed-phase of preconditioning. Using an in vivo approach, we subjected both Cav-1 and Cav-3 deficient mice to isoflurane exposure, followed by $24 \mathrm{~h}$ of recovery prior to IR, and observed that both the formation of morphologic caveolae and induced cardioprotection during delayed IPC was a Cav-3 dependent event (Tsutsumi et al., 2010). The time-course of cardioprotection appeared to coincide with translocation of Glut-4 to caveolae, with co-localization of Cav-3/Glut- 4 complexes within the LV. Moreover, while early disruption of caveolae in cardiomyocytes did not disrupt delayed cardioprotection, disruption of caveolae following $24 \mathrm{~h}$ after isoflurane exposure (but just prior to IR) did, implicating morphologic caveolae as necessary mediators in the late-phase of APC (Tsutsumi et al., 2010). Collectively these studies suggest that Cav-3 is both necessary and sufficient to promote the formation of caveolae and to induce both early and delayed cardiac protection from IR injury. Interestingly, a recent study by Waldenström et al. demonstrated that cardiomyocytes secrete MLR-like microvescicle "exosomes" that contain Cav-3 (Waldenstrom et al., 2012), raising the intriguing possibility that control of cell signaling may not be spatially restricted to a single cell, and that caveolins may play a role in inter-cellular and possibly inter-organ communication. Although our understanding of the mechanisms by which caveolins and MLRs provide cardiac protection remains incomplete, it appears that caveolin-induced enhancement of pro-survival and pro-growth pathways offers a promising avenue for clinical trials in the treatment of multiple diseases of the heart.

\section{CAVEOLIN-1 REGULATES NEURONAL SIGNALING}

Although it is now recognized that all three caveolin isoforms exist in neurons, a discreet absence of caveolae likely contributed to the late recognition that caveolins are not only present within neuronal cell membranes but also contribute to neuronal prosurvival signaling (for review see Stern and Mermelstein (2010). Caveolin-dependent signaling appears to be mediated by spatial localization of relevant molecules, either through clustering and sequestering, thereby exerting both positive and negative regulation of signaling (Galbiati et al., 1998). For example, while Cav-1 knockdown impedes mobilization of intracellular $\mathrm{Ca}^{2+}$ by serotonin 2A subtype-receptor (Bhatnagar et al., 2004), Cav-1 appears to internalize and attenuate the activity of the Gascoupled dopamine receptor (Kong et al., 2007). Localization of signaling is important in the neuron, as extra-synaptic activation may induce excitotoxicity (Figure 2), promoting cell death (Hardingham and Bading, 2003). In neurons, Cav-1 co-localizes with the synaptic-specific protein PSD-95 (Boeckers, 2006), and with the pro-survival signaling receptors such as the NMDA glutamate receptor subtype $2 \mathrm{~A}$, indicating spatial regulation of neuronal signaling (Head et al., 2008). Targeting of caveolin to the synapse suggests the pivotal role they are thought to play in synaptic development of retinal ganglion cells (Mauch et al., 2001) and at the neuromuscular junction (Willmann et al., 2006). Cav-1 is expressed in multiple types of neurons, including hippocampal and dorsal root ganglion neurons (Galbiati

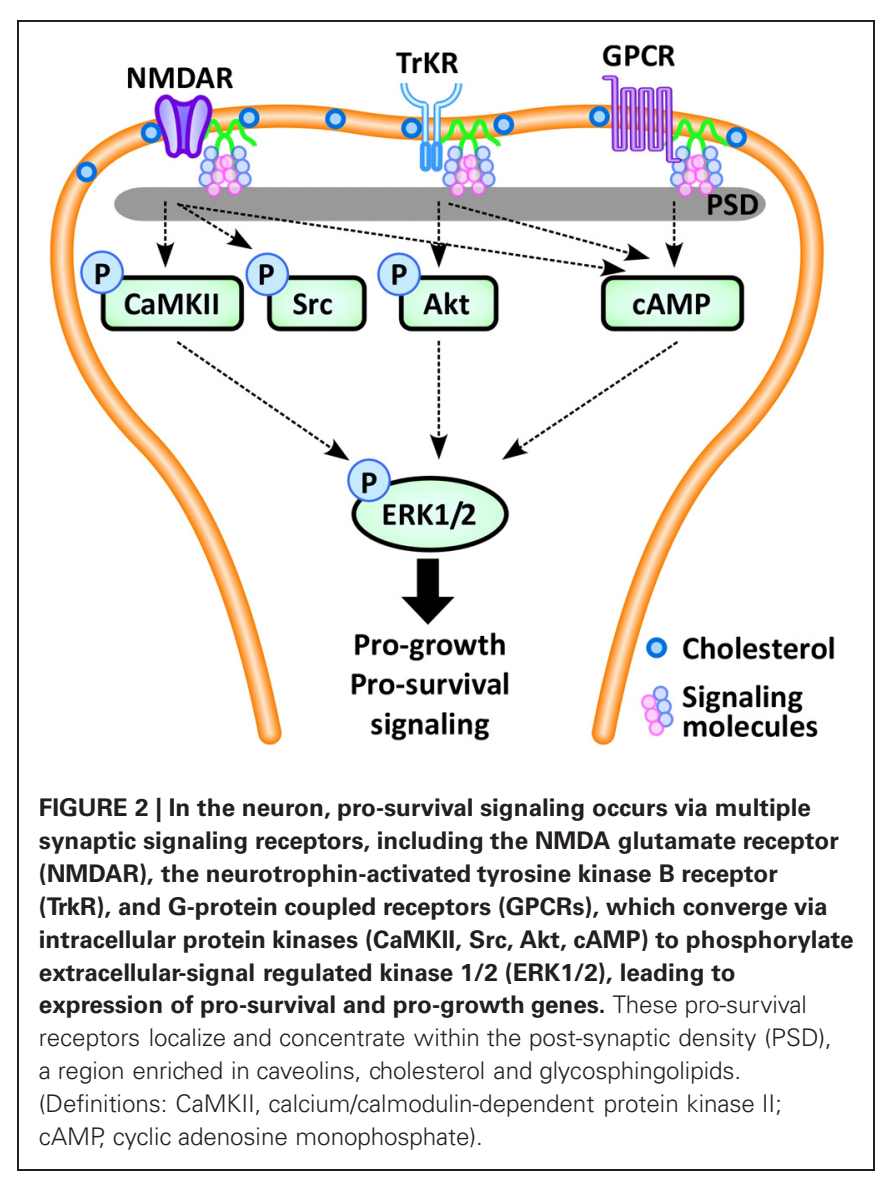

et al., 1998; Peiro et al., 2000; Bu et al., 2003; Gaudreault et al., 2004), and Cav-1 deficient mice exhibit neurological abnormalities including, abnormal spinning, muscle weakness, reduced activity, and gait abnormalities (Trushina et al., 2006). Additional work demonstrates that Cav-1 KO mice exhibit an early aging phenotype, which includes loss of synapses, enhanced astrogliosis and changes in the cerebrovasculature (Head et al., 2010). Interestingly, Cohen et al. note in unpublished observations that Cav-1 KO mice display an increased sensitivity to inhaled anesthetics (Cohen et al., 2003), resulting in profound bradycardia given a standard level of anesthetic. Whether these observations are mediated by a central or peripheral mechanism is unclear. One intriguing phenomenon proposed by Lucchinetti et al. (2008) considers the preferential partitioning of halogenated ethers to amphiphilic interfaces [such as lipid rafts (Morgan et al., 2004)] as a significant event in cell signaling, whereby exposure to anesthetics may alter the interaction of specific protein-protein and/or protein-lipid interactions, thereby resulting in remodeling of the signaling architecture within the cell. As noted above, we have observed this in cardiomyocytes (Patel et al., 2007), whereby exposure to isoflurane resulted in an increase in morphological caveolae, supporting a mechanism where halogenated ethers alter the physiochemistry of the cell membrane. However, given that neurons do not exhibit morphologic caveolae it remains unclear whether MLRs in fact play a significant role in the anesthetic effects of halogenated ethers in the CNS. 
Currently this area has not been investigated and remains largely unknown.

Similar to myocardium, caveolins in neurons coordinate GPCRs, ion channels, and downstream kinase activation. Pro-survival signaling in neurons occurs following activation of a number of synaptic receptors, including GPCRs, the neurotrophin-activated tyrosine kinase $\mathrm{B}(\operatorname{TrkB})$ receptor, and the glutamate receptor, which share the common final pathway of phosphorylation of the CAMP response element binding protein (CREB), initiating transcription of pro-growth genes (Figure 2). Cav-1 and MLRs can regulate estrogen GPCR signaling (Mermelstein, 2009), whereas Cav-3 inhibition leads to loss of the estrogen-mediated inhibition of L-type $\mathrm{Ca}^{2+}$ channeldependent CREB phosphorylation (Boulware et al., 2007). This latter effect may lead to $\mathrm{Ca}^{2+}$ flux and potentially neuromuscular contraction, synaptic transmission or upregulation of gene expression. Ionotropic receptor, TrkB-receptor, and GPCRmediated neurotransmission appear to be caveolin-dependent (Head et al., 2008, 2011; Francesconi et al., 2009; Takayasu et al., 2010). Positive regulation of $5-\mathrm{HT}_{2 A} \mathrm{R}$, a subtype of GPCR, likely occurs through facilitating binding between the receptor and G $\alpha$ q subunit (Bhatnagar et al., 2004). Similarly, the activation of the NMDA receptor appears to be mediated by both Cav-1 and Cav-3 via controlled coordination of the Gaq subunit, with subsequent modulation of the pro-growth pathway ERK1/2 (Head et al., 2008). For example, we demonstrated that loss of Cav-1 expression disrupts NMDA receptor signaling and attenuates prosurvival Src and ERK1/2 phosphorylation in response to NMDA or simulated ischemia (Head et al., 2008, 2011).

\section{CAVEOLIN-1 PROTECTS NEURONS FROM ISCHEMIC INJURY AND PROMOTES DENDRITIC GROWTH}

Cerebral ischemia decreases the integrity of cell membranes and thus may disrupt caveolin-associated signaling complexes. A neuroprotective role for Cav-1 was first demonstrated in Cav-1 KO mice, which had a larger cerebral infarct size in response to ischemia (Jasmin et al., 2007) that may have been due to alterations in the permeability of the blood brain barrier ( $\mathrm{Gu}$ et al., 2012) secondary to Cav-1 related translocation of the tightjunction protein claudin-5 (Liu et al., 2012). It was subsequently demonstrated that intracerebral hemorrhage resulted in elevated inflammatory mediators and a larger region of neuronal cell death in Cav-1 KO mice (Chang et al., 2011). This may be due to the complex role that signaling receptors are thought to play in the developing brain (Li et al., 1998), whereby disruption of MLRs results in multiple signaling deficiencies (Mauch et al., 2001; Willmann et al., 2006). Our laboratories corroborated the essential role of Cav-1 in phosphorylation of Src and ERK1/2 and IPC, by demonstrating that Cav-1 deficient neurons were unable to undergo preconditioning, while return of Cav-1 restored the capacity of the neuron to undergo the cytoprotective effect (Head et al., 2008, 2011). In addition to greater sensitivity to ischemia, mice deficient in Cav-1 have a CNS pathology similar to that exhibited in neurodegenerative diseases, including altered glutamate receptor signaling (Head et al., 2008; Francesconi et al., 2009; Takayasu et al., 2010), and impaired cholinergic function (Trushina et al., 2006; Jasmin et al., 2007; Gioiosa et al., 2008).
A role for caveolin-associated neurodegenerative disorders may be found in the lipid composition of the MLR (Parton, 1994), in particular GM-gangliosides, which are concentrated within MLRs and have been associated with autoimmune disorders such as lupus and Guillain-Barré syndrome (Bansal et al., 1994), in addition to being implicated in the development of dementia (Bansal et al., 1994). Interestingly, in post-mortem samples of human hippocampus and cortex in patients with Alzheimer's disease, cytospatial distribution of Cav-1 and the voltage-dependent anion channel (VDAC) is increased (Ramirez et al., 2009). Since the VDAC is thought to play a role in Alzheimer's-associated amyloid- $\beta$ neurotoxicity (Ferrer, 2009), caveolins may play a prominent role in the modulation of amyloid precursor protein processing, and thus the development and progression of Alzheimer's disease. For example, functional Cav-1 plays a role in HIV-related accumulation of amyloid- $\beta$ (Andras et al., 2012), while Cav-1 deficient mice develop a pathological phenotype similar to that of Alzheimer's disease (Head et al., 2010). Aging increases the likelihood of dementia and Alzheimer's disease, and localization of synaptic signaling components in neuronal MLRs is reduced in brains from aged WT and young Cav-1 KO mice (Head et al., 2010). Clearly, more research is needed on the regulatory role of caveolins/MLR on the activity of key secretases involved in amyloid processing.

Functional recovery from brain injury (i.e., stroke or trauma) and neurodegeneration is limited by a reduction in pro-survival and pro-growth signaling (Atkins et al., 2007), which increases neuronal loss, impairs brain repair, and increases functional deficits. This may explain why exogenous pharmacologic interventions targeting pro-survival pathways individually have been relatively ineffective. We have demonstrated that loss of Cav-1 decreases expression of MLRs, neurotransmitter and neurotrophin receptors, impairs neurotransmitter transduction, and attenuates pro-survival signaling (Head et al., 2008, 2011). A recent study (Lim et al., 2011), demonstrating that administration of exogenous gangliosides, a component of the MLR, resulted in augmentation of neurotrophic signaling in rat hippocampal and human neuronal cell lines, providing evidence that restoration of signaling may promote neuronal growth and improve functional outcome. However non-specific augmentation in pro-growth signaling may promote neoplastic processes, as there is evidence that the development of glioma is associated with increased Cav-1 production in astrocytes (Parat and Riggins, 2012). To this end, our laboratory utilized the neuron-specific promoter synapsin to overexpress Cav-1, which led to enhanced expression of MLRs, neurotransmitter and neurotrophin receptors specifically in neurons (Head et al., 2011). This resulted in an increase in pro-survival and pro-growth signaling molecules, translating to dendritic growth and arborization, even in the presence of inhibitory mediators. These promising results demonstrate that restoration of pro-survival and pro-growth signaling may be both necessary and sufficient to provide a therapeutic benefit in the functional recovery from brain injury and neurodegeneration.

\section{CONCLUSIONS}

In the years following George Palade's first observations of caveolae nearly 60 years ago, diffusion-based fluid-mosaic models of 
the cell surface membrane (Singer and Nicolson, 1972) could not account for the speed and fidelity with which intracellular signaling occurs. It is clear now that the complexity of orchestrating multiple sub-cellular signaling events is accomplished by the focal concentration of signaling moieties within the MLR. This highly organized structure is dependent on caveolins, which facilitate and coordinate the spatial and temporal organization necessary to achieve multiple, simultaneous signaling activities. However, the model that caveolin is the only structural protein necessary for the formation of caveolae is becoming more complex with the description of the "cavin" family of proteins and other membrane proteins such as pacsin-2/syndapin-2, which are now known to play a key role in the formation and function of caveolae (Hansen and Nichols, 2010; Briand et al., 2011). Future work will need to focus on how the interaction of caveolins, cavins and other membrane structural proteins in and out of caveolar microdomains influences the potential pro-survival role of caveolins in the heart and brain.

By augmenting the expression of caveolin in the heart and brain, multiple pro-survival and pro-growth pathways are simultaneously upregulated, which is sufficient, and likely necessary, for inducing cardiac and neuroprotection. It remains to be resolved how control of caveolin expression can be harnessed in a clinical fashion to produce a beneficial therapeutic outcome. In addition to developing a gene delivery vehicle that is safe and efficacious in patients, post-transcriptional regulators such as RNAses and micro-RNAs may be able to be engineered to affect the gene expression machinery to augment potential protein therapies. Micro-RNAs ("miRs") are small non-coding RNAs that serve to regulate post-transcriptional gene expression by binding to mRNA and repressing translation or degrading mRNA entirely. They are highly abundant in the brain and have been known to localize to subcellular regions such as dendritic spines and can affect spine structure/morphology, function, and synaptic plasticity (Gao et al., 2010; Saugstad, 2010). Although cell-specific genetic manipulation in vivo via viral vector delivery (e.g., adenoviral, adeno-associated viruses) has great therapeutic/translational potential, the use of small molecules to induce cell specific enhancement in mRNA translation will allow us to achieve alterations in protein expression-independent of viral vectors. An example is the use of complementary inhibitors of miRs, termed "antagomirs." In regard to caveolin-specific miR inhibition, one group showed that the use of antagomirs to block Cav-1 associated miRs (miRs 103/107) and subsequently enhance Cav-1 protein expression reversed a type II diabetic phenotype (Trajkovski et al., 2011). Because caveolins afford robust protection against ischemic injury in both cardiac and neuronal tissue, identifying caveolin miRs specifically in the heart, brain, and spinal cord may allow us to design effective antagomirs with significant pharmaceutical implications. Given the potential of caveolin therapy to augment pro-growth signaling pathways, technologies to control the temporal expression of caveolins may be necessary as an "on-off" switch to prevent neoplasia. Although many aspects of harnessing the spatial and temporal regulation of cell signaling by caveolins remain to be determined, the studies described above represent a promising new therapeutic approach in which targeting cell survival signaling via caveolin expression may prove to not only augment existing pharmacologic modalities aimed at individual pro-survival pathways, but may alone be sufficient to promote cell survival and growth in a number of diseases of the heart and brain.

\section{ACKNOWLEDGMENTS}

This work was supported by National Institutes of Health Grants HL091071 (awarded to Hemal H. Patel), HL107200 (awarded to Hemal H. Patel and David M. Roth), NS073653 (awarded to Brain P. Head), GM085179 (awarded to Piyush M. Patel), and HL081400 (awarded to David M. Roth), and by Veterans Administration Merit Awards BX001225 (awarded to Brian P. Head) and BX000783 (awarded to David M. Roth).

\section{REFERENCES}

Anderson, R. G. (1993). Potocytosis of small molecules and ions by caveolae. Trends Cell Biol. 3, 69-72.

Andras, I. E., Eum, S. Y., and Toborek, M. (2012). Lipid rafts and functional caveolae regulate HIV-induced amyloid beta accumulation in brain endothelial cells. Biochem. Biophys. Res. Commun. 421, 177-183.

Aravamudan, B., Volonte, D., Ramani, R., Gursoy, E., Lisanti, M. P., London, B., et al. (2003). Transgenic overexpression of caveolin-3 in the heart induces a cardiomyopathic phenotype. Hum. Mol. Genet. 12, 2777-2788.

Atkins, C. M., Falo, M. C., Alonso, O. F., Bramlett, H. M., and Dietrich, W. D. (2009). Deficits in ERK and CREB activation in the hippocampus after traumatic brain injury. Neurosci. Lett. 459, 52-56.
Atkins, C. M., Oliva, A. A. J., Alonso, O. F., Pearse, D. D., Bramlett, H. M., and Dietrich, W. D. (2007). Modulation of the cAMP signaling pathway after traumatic brain injury. Exp. Neurol. 208, 145-158.

Balijepalli, R. C., Foell, J. D., Hall, D. D., Hell, J. W., and Kamp, T. J. (2006). Localization of cardiac Ltype $\mathrm{Ca}(2+)$ channels to a caveolar macromolecular signaling complex is required for beta(2)-adrenergic regulation. Proc. Natl. Acad. Sci. U.S.A. 103, 7500-7505.

Balijepalli, R. C., and Kamp, T. J. (2008). Caveolae, ion channels and cardiac arrhythmias. Prog. Biophys. Mol. Biol. 98, 149-160.

Balse, E., Steele, D. F., Abriel, H., Coulombe, A., Fedida, D., and Hatem, S. N. (2012). Dynamic of ion channel expression at the plasma membrane of cardiomyocytes. Physiol. Rev. 92, 1317-1358.
Bansal, A. S., Abdul-Karim, B., Malik, R. A., Goulding, P., Pumphrey, R. S., Boulton, A. J., et al. (1994). IgM ganglioside GM1 antibodies in patients with autoimmune disease or neuropathy, and controls. J. Clin. Pathol. 47, 300-302.

Bergdahl, A., Gomez, M. F., Dreja, K., Xu, S. Z., Adner, M., Beech, D. J., et al. (2003). Cholesterol depletion impairs vascular reactivity to endothelin-1 by reducing storeoperated $\mathrm{Ca} 2+$ entry dependent on TRPC1. Circ. Res. 93, 839-847.

Besse, I. M., Mitchell, C. C., Hund, T. J., and Shibata, E. F. (2011). A computational investigation of cardiac caveolae as a source of persistent sodium current. Front. Physiol. 2:87. doi: 10.3389/fphys.2011.00087

Bhatnagar, A., Sheffler, D. J., Kroeze, W. K., Compton-Toth, B., and Roth, B. L. (2004). Caveolin-1 interacts with 5-HT2A serotonin receptors and profoundly modulates the signaling of selected Galphaq-coupled protein receptors. J. Biol. Chem. 279, 34614-34623.

Biegon, A., Fry, P. A., Paden, C. M., Alexandrovich, A., Tsenter, J., and Shohami, E. (2004). Dynamic changes in $\mathrm{N}$-methyl-D-aspartate receptors after closed head injury in mice: implications for treatment of neurological and cognitive deficits. Proc. Natl. Acad. Sci. U.S.A. 101, 5117-5122.

Blair, A., Shaul, P. W., Yuhanna, I. S., Conrad, P. A., and Smart, E. J. (1999). Oxidized low density lipoprotein displaces endothelial nitric-oxide synthase (eNOS) from plasmalemmal caveolae and impairs eNOS activation. J. Biol. Chem. 274, 32512-32519.

Boeckers, T. M. (2006). The postsynaptic density. Cell Tissue Res. 326, 409-422. 
Boscher, C., and Nabi, I. R. (2012). Caveolin-1, role in cell signaling. Adv. Exp. Med. Biol. 729, 29-50.

Boulware, M. I., Kordasiewicz, H., and Mermelstein, P. G. (2007). Caveolin proteins are essential for distinct effects of membrane estrogen receptors in neurons. J. Neurosci. 27, 9941-9950.

Briand, N., Dugail, I., and Le Lay, S. (2011). Cavin proteins: new players in the caveolae field. Biochimie 93, 71-77.

Bu, J., Bruckner, S. R., Sengoku, T., Geddes, J. W., and Estus, S. (2003). Glutamate regulates caveolin expression in rat hippocampal neurons. J. Neurosci. Res. 72, 185-190.

Bucci, M., Gratton, J. P., Rudic, R. D., Acevedo, L., Roviezzo, F., Cirino, G., et al. (2000). In vivo delivery of the caveolin-1 scaffolding domain inhibits nitric oxide synthesis and reduces inflammation. Nat. Med. 6, 1362-1367.

Cason, B. A., Gamperl, A. K., Slocum, R. E., and Hickey, R. F. (1997). Anesthetic-induced preconditioning: previous administration of isoflurane decreases myocardial infarct size in rabbits. Anesthesiology 87, 1182-1190.

Chang, C. F., Chen, S. F., Lee, T. S., Lee, H. F., Chen, S. F., and Shyue, S. K. (2011). Caveolin-1 deletion reduces early brain injury after experimental intracerebral hemorrhage. Am. J. Pathol. 178, 1749-1761.

Cheng, H., and Lederer, W. J. (2008). Calcium sparks. Physiol. Rev. 88, 1491-1545.

Chiari, P. C., Bienengraeber, M. W., Weihrauch, D., Krolikowski, J. G., Kersten, J. R., Warltier, D. C., et al. (2005). Role of endothelial nitric oxide synthase as a trigger and mediator of isofluraneinduced delayed preconditioning in rabbit myocardium. Anesthesiology 103, 74-83.

Cho, W. J., Chow, A. K., Schulz, R., and Daniel, E. E. (2010). Caveolin1 exists and may function in cardiomyocytes. Can. J. Physiol. Pharmacol. 88, 73-76.

Cohen, A. W., Park, D. S., Woodman, S. E., Williams, T. M., Chandra, M., Shirani, J., et al. (2003). Caveolin-1 null mice develop cardiac hypertrophy with hyperactivation of $\mathrm{p} 42 / 44$ MAP kinase in cardiac fibroblasts. Am. J. Physiol. Cell Physiol. 284, C457-C474.

Cruz, J. A., Bauer, E. M., Rodriguez, A. I., Gangopadhyay, A., Zeineh, N. S., Wang, Y., et al. (2012). Chronic hypoxia induces right heart failure in caveolin-1-/- mice. Am. J.
Physiol. Heart Circ. Physiol. 302, H2518-H2527.

Dietzen, D. J., Hastings, W. R., and Lublin, D. M. (1995). Caveolin is palmitoylated on multiple cysteine residues. Palmitoylation is not necessary for localization of caveolin to caveolae. J. Biol. Chem. 270, 6838-6842.

Doyle, D. D., Ambler, S. K., UpshawEarley, J., Bastawrous, A., Goings, G. E., and Page, E. (1997). Type B atrial natriuretic peptide receptor in cardiac myocyte caveolae. Circ. Res. 81, 86-91.

Drab, M., Verkade, P., Elger, M., Kasper, M., Lohn, M., Lauterbach, B., et al. (2001). Loss of caveolae, vascular dysfunction, and pulmonary defects in caveolin-1 gene-disrupted mice. Science 293, 2449-2452.

Dupree, P., Parton, R. G., Raposo, G., Kurzchalia, T. V., and Simons, K. (1993). Caveolae and sorting in the trans-Golgi network of epithelial cells. EMBO J. 12, 1597-1605.

El-Yazbi, A. F., Cho, W. J., Boddy, G., Schulz, R., and Daniel, E. E. (2006). Impact of caveolin-1 knockout on NANC relaxation in circular muscles of the mouse small intestine compared with longitudinal muscles. Am. J. Physiol. Gastrointest. Liver Physiol. 290, G394-G403.

Engelman, J. A., Chu, C., Lin, A., Jo, H., Ikezu, T., Okamoto, T., et al. (1998). Caveolin-mediated regulation of signaling along the p42/44 MAP kinase cascade in vivo. A role for the caveolin-scaffolding domain. FEBS Lett. 428, 205-211.

Escriche, M., Burgueno, J., Ciruela, F., Canela, E. I., Mallol, J., Enrich, C., et al. (2003). Ligand-induced caveolae-mediated internalization of Al adenosine receptors: morphological evidence of endosomal sorting and receptor recycling. Exp. Cell Res. 285, 72-90.

Fagan, K. A., Smith, K. E., and Cooper, D. M. (2000). Regulation of the Ca2+-inhibitable adenylyl cyclase type VI by capacitative Ca2+ entry requires localization in cholesterolrich domains. J. Biol. Chem. 275, 26530-26537.

Feng, Y., Venema, V. J., Venema, R. C., Tsai, N., Behzadian, M. A., and Caldwell, R. B. (1999). VEGFinduced permeability increase is mediated by caveolae. Invest. Ophthalmol. Vis. Sci. 40, 157-167.

Feron, O., Belhassen, L., Kobzik, L., Smith, T. W., Kelly, R. A., and Michel, T. (1996). Endothelial nitric oxide synthase targeting to caveolae. Specific interactions with caveolin isoforms in cardiac myocytes and endothelial cells. J. Biol. Chem. 271, 22810-22814.

Feron, O., Dessy, C., Opel, D. J., Arstall, M. A., Kelly, R. A., and Michel, T. (1998). Modulation of the endothelial nitric-oxide synthase-caveolin interaction in cardiac myocytes. Implications for the autonomic regulation of heart rate. J. Biol. Chem. 273, 30249-30254.

Ferrer, I. (2009). Altered mitochondria, energy metabolism, voltagedependent anion channel, and lipid rafts converge to exhaust neurons in Alzheimer's disease. J. Bioenerg. Biomembr. 41, 425-431.

Francesconi, A., Kumari, R., and Zukin, R. S. (2009). Regulation of group I metabotropic glutamate receptor trafficking and signaling by the caveolar/lipid raft pathway. $J$. Neurosci. 29, 3590-3602.

Fujimoto, T. (1993). Calcium pump of the plasma membrane is localized in caveolae. J. Cell Biol. 120, 1147-1157.

Fujimoto, T., Nakade, S., Miyawaki, A., Mikoshiba, K., and Ogawa, K. (1992). Localization of inositol 14 , 5-trisphosphate receptor-like protein in plasmalemmal caveolae. $J$. Cell Biol. 119, 1507-1513.

Galbiati, F., Engelman, J. A., Volonte, D., Zhang, X. L., Minetti, C. Li, M., et al. (2001). Caveolin-3 null mice show a loss of caveolae, changes in the microdomain distribution of the dystrophinglycoprotein complex, and t-tubule abnormalities. J. Biol. Chem. 276, 21425-21433

Galbiati, F., Volonte, D., Chu, J. B. Li, M., Fine, S. W., Fu, M., et al. (2000). Transgenic overexpression of caveolin-3 in skeletal muscle fibers induces a Duchenne-like muscular dystrophy phenotype. Proc. Natl. Acad. Sci. U.S.A. 97, 9689-9694.

Galbiati, F., Volonte, D., Gil, O., Zanazzi, G., Salzer, J. L., Sargiacomo, M., et al. (1998). Expression of caveolin-1 and -2 in differentiating PC12 cells and dorsal root ganglion neurons: caveolin-2 is up-regulated in response to cell injury. Proc. Natl. Acad. Sci. U.S.A. 95, 10257-10262.

Gao, J., Wang, W. Y., Mao, Y. W., Graff, J., Guan, J. S., Pan, L., et al. (2010). A novel pathway regulates memory and plasticity via SIRT1 and miR134. Nature 466, 1105-1109.

Gaudreault, S. B., Chabot, C., Gratton, J. P., and Poirier, J. (2004). The caveolin scaffolding domain modifies 2-amino-3-hydroxy-5methyl-4-isoxazole propionate receptor binding properties by inhibiting phospholipase A2 activity. J. Biol. Chem. 279, 356-362.

Gioiosa, L., Raggi, C., Ricceri, L., Jasmin, J. F., Frank, P. G., Capozza, F., et al. (2008). Altered emotionality, spatial memory and cholinergic function in caveolin-1 knockout mice. Behav. Brain Res. 188 255-262.

Gu, Y., Zheng, G., Xu, M., Li, Y., Chen, X., Zhu, W., et al. (2012). Caveolin1 regulates nitric oxide-mediated matrix metalloproteinases activity and blood-brain barrier permeability in focal cerebral ischemia and reperfusion injury. J. Neurochem. 120, 147-156.

Guo, Y., Golebiewska, U., and Scarlata, S. (2011). Modulation of $\mathrm{Ca}(2)+$ activity in cardiomyocytes through caveolae-Galphaq interactions. Biophys. J. 100, 1599-1607.

Hagiwara, Y., Sasaoka, T., Araishi, K., Imamura, M., Yorifuji, H., Nonaka, I., et al. (2000). Caveolin-3 deficiency causes muscle degeneration in mice. Hum. Mol. Genet. 9, 3047-3054.

Hansen, C. G., and Nichols, B. J. (2010). Exploring the caves: cavins, caveolins and caveolae. Trends Cell Biol. 20, 177-186.

Hardingham, G. E., and Bading, $\mathrm{H}$. (2003). The Yin and Yang of NMDA receptor signalling. Trends Neurosci. 26, 81-89.

Head, B. P., Hu, Y., Finley, J. C., Saldana, M. D., Bonds, J. A., Miyanohara, A., et al. (2011). Neuron-targeted caveolin-1 protein enhances signaling and promotes arborization of primary neurons. J. Biol. Chem. 286, 33310-33321.

Head, B. P., Patel, H. H., Tsutsumi, Y. M., Hu, Y., Mejia, T., Mora, R. C., et al. (2008). Caveolin-1 expression is essential for N-methyl-Daspartate receptor-mediated Src and extracellular signal-regulated kinase $1 / 2$ activation and protection of primary neurons from ischemic cell death. FASEB J. 22, 828-840.

Head, B. P., Peart, J. N., Panneerselvam, M., Yokoyama, T., Pearn, M. L., Niesman, I. R., et al. (2010). Loss of caveolin-1 accelerates neurodegeneration and aging. PLOS ONE 5:e15697. doi: 10.1371/journal.pone.0015697

Hicks, R. R., Zhang, L., Dhillon, H. S., Prasad, M. R., and Seroogy, K. B. (1998). Expression of trkB mRNA is altered in rat hippocampus after experimental brain trauma. Brain Res. Mol. Brain Res. 59, 264-268.

Horikawa, Y. T., Panneerselvam, M., Kawaraguchi, Y., Tsutsumi, Y. M., Ali, S. S., Balijepalli, R. C., et al. (2011). Cardiac-specific 
overexpression of caveolin-3 attenuates cardiac hypertrophy and increases natriuretic peptide expression and signaling. J. Am. Coll. Cardiol. 57, 2273-2283.

Horikawa, Y. T., Patel, H. H., Tsutsumi, Y. M., Jennings, M. M., Kidd, M. W., Hagiwara, Y., et al. (2008). Caveolin-3 expression and caveolae are required for isoflurane-induced cardiac protection from hypoxia and ischemia/reperfusion injury. J. Mol. Cell Cardiol. 44, 123-130.

Hoyert, D. L. (2012). 75 years of mortality in the United States, 1935-2010. NCHS Data Brief 88, $1-8$.

Insel, P. A., Head, B. P., Patel, H. H., Roth, D. M., Bundey, R. A., and Swaney, J. S. (2005). Compartmentation of G-proteincoupled receptors and their signalling components in lipid rafts and caveolae. Biochem. Soc. Trans. 33, 1131-1134.

Jasmin, J. F., Malhotra, S., Singh Dhallu, M., Mercier, I., Rosenbaum, D. M., and Lisanti, M. P. (2007). Caveolin-1 deficiency increases cerebral ischemic injury. Circ. Res. 100, 721-729.

Kersten, J. R., Schmeling, T. J., Pagel, P. S., Gross, G. J., and Warltier, D. C. (1997). Isoflurane mimics ischemic preconditioning via activation of K(ATP) channels: reduction of myocardial infarct size with an acute memory phase. Anesthesiology 87, 361-370.

Koga, A., Oka, N., Kikuchi, T., Miyazaki, H., Kato, S., and Imaizumi, T. (2003). Adenovirusmediated overexpression of caveolin-3 inhibits rat cardiomyocyte hypertrophy. Hypertension 42, 213-219.

Kong, M. M., Hasbi, A., Mattocks, M., Fan, T., O'Dowd, B. F., and George, S. R. (2007). Regulation of D1 dopamine receptor trafficking and signaling by caveolin-1. Mol. Pharmacol. 72, 1157-1170.

Krajewska, W. M., and Maslowska, I. (2004). Caveolins: structure and function in signal transduction. Cell Mol. Biol. Lett. 9, 195-220.

Kwiatek, A. M., Minshall, R. D., Cool, D. R., Skidgel, R. A., Malik, A. B., and Tiruppathi, C. (2006). Caveolin-1 regulates store-operated $\mathrm{Ca} 2+$ influx by binding of its scaffolding domain to transient receptor potential channel-1 in endothelial cells. Mol. Pharmacol. 70, 1174-1183.

Labrecque, L., Royal, I., Surprenant, D. S., Patterson, C., Gingras, D., and Beliveau, R. (2003). Regulation of vascular endothelial growth factor receptor- 2 activity by caveolin- 1 and plasma membrane cholesterol. Mol. Biol. Cell 14, 334-347.

Li, J. H., Wang, Y. H., Wolfe, B. B., Krueger, K. E., Corsi, L., Stocca, G., et al. (1998). Developmental changes in localization of NMDA receptor subunits in primary cultures of cortical neurons. Eur. J. Neurosci. 10, 1704-1715.

Li, S., Okamoto, T., Chun, M., Sargiacomo, M., Casanova, J. E., Hansen, S. H., et al. (1995). Evidence for a regulated interaction between heterotrimeric $\mathrm{G}$ proteins and caveolin. J. Biol. Chem. 270 15693-15701.

Li, S., Song, K. S., and Lisanti, M. P. (1996). Expression and characterization of recombinant caveolin. Purification by polyhistidine tagging and cholesterol-dependent incorporation into defined lipid membranes. J. Biol. Chem. 271, 568-573.

Lim, S. T., Esfahani, K., Avdoshina, V., and Mocchetti, I. (2011). Exogenous gangliosides increase the release of brain-derived neurotrophic factor. Neuropharmacology 60, 1160-1167.

Lisanti, M. P., Scherer, P. E., Tang, Z., and Sargiacomo, M. (1994). Caveolae, caveolin and caveolinrich membrane domains: a signalling hypothesis. Trends Cell Biol. 4, 231-235.

Liu, J., Jin, X., Liu, K. J., and Liu, W. (2012). Matrix metalloproteinase2-mediated occludin degradation and caveolin-1-mediated claudin-5 redistribution contribute to bloodbrain barrier damage in early ischemic stroke stage. J. Neurosci. 32, 3044-3057.

Lohn, M., Furstenau, M., Sagach, V., Elger, M., Schulze, W., Luft, F. C., et al. (2000). Ignition of calcium sparks in arterial and cardiac muscle through caveolae. Circ. Res. 87, 1034-1039.

Lucchinetti, E., Schaub, M. C., and Zaugg, M. (2008). Emulsified intravenous versus evaporated inhaled isoflurane for heart protection: old wine in a new bottle or true innovation? Anesth. Analg. 106, 1346-1349.

Macdougall, D. A., Agarwal, S. R., Stopford, E. A., Chu, H., Collins, J. A., Longster, A. L., et al. (2012). Caveolae compartmentalise beta2adrenoceptor signals by curtailing cAMP production and maintaining phosphatase activity in the sarcoplasmic reticulum of the adult ventricular myocyte. J. Mol. Cell Cardiol. 52, 388-400.

Maguy, A., Hebert, T. E., and Nattel, S. (2006). Involvement of lipid rafts and caveolae in cardiac ion channel function. Cardiovasc. Res. 69, 798-807.

Makarewich, C. A., Correll, R. N., Gao, H., Zhang, H., Yang, B., Berretta, R. M., et al. (2012) A caveolae-targeted L-type $\mathrm{Ca}(2)+$ channel antagonist inhibits hypertrophic signaling without reducing cardiac contractility. Circ. Res. 110, 669-674.

Markandeya, Y. S., Fahey, J. M., Pluteanu, F., Cribbs, L. L., and Balijepalli, R. C. (2011). Caveolin-3 regulates protein kinase $\mathrm{A}$ modulation of the $\mathrm{Ca}(\mathrm{V}) 3.2$ (alpha1H) T-type $\mathrm{Ca} 2+$ channels. J. Biol. Chem. 286, 2433-2444.

Marler, J. R. (2007). NINDS clinical trials in stroke: lessons learned and future directions. Stroke 38, 3302-3307.

Martens, J. R., Sakamoto, N., Sullivan, S. A., Grobaski, T. D., and Tamkun, M. M. (2001). Isoform-specific localization of voltage-gated $\mathrm{K}+$ channels to distinct lipid raft populations. Targeting of Kv1.5 to caveolae. J. Biol. Chem. 276, 8409-8414.

Mauch, D. H., Nagler, K., Schumacher, S., Goritz, C., Muller, E. C., Otto, A., et al. (2001). CNS synaptogenesis promoted by glia-derived cholesterol. Science 294, 1354-1357.

Mermelstein, P. G. (2009). Membranelocalised oestrogen receptor alpha and beta influence neuronal activity through activation of metabotropic glutamate receptors. J. Neuroendocrinol. 21, 257-262.

Monier, S., Parton, R. G., Vogel, F., Behlke, J., Henske, A., and Kurzchalia, T. V. (1995). VIP21caveolin, a membrane protein constituent of the caveolar coat, oligomerizes in vivo and in vitro. Mol. Biol. Cell 6, 911-927.

Morgan, P. G., Hubbard, M., Eckenhoff, R. G., and Sedensky, M. M. (2004). Halothane partitions to lipid rafts in C. elegans. Anesthesiology 101, A105.

Murata, M., Peranen, J., Schreiner, R., Wieland, F., Kurzchalia, T. V., and Simons, K. (1995). VIP21/caveolin is a cholesterol-binding protein. Proc. Natl. Acad. Sci. U.S.A. 92, 10339-10343.

Murry, C. E., Jennings, R. B., and Reimer, K. A. (1986). Preconditioning with ischemia: a delay of lethal cell injury in ischemic myocardium. Circulation 74, 1124-1136

Newman, T. M., Severs, N. J., and Skepper, J. N. (1991). The pathway of atrial natriuretic peptide releasefrom cell to plasma. Cardioscience 2, 263-272.
Nishino, Y., Miura, T., Miki, T., Sakamoto, J., Nakamura, Y., Ikeda, Y., et al. (2004). Ischemic preconditioning activates AMPK in a PKC-dependent manner and induces GLUT4 up-regulation in the late phase of cardioprotection. Cardiovasc. Res. 61, 610-619.

O'Connell, K. M., Martens, J. R., and Tamkun, M. M. (2004). Localization of ion channels to lipid Raft domains within the cardiovascular system. Trends Cardiovasc. Med. 14, 37-42.

Oh, P., and Schnitzer, J. E. (2001). Segregation of heterotrimeric $\mathrm{G}$ proteins in cell surface microdomains. G(q) binds caveolin to concentrate in caveolae, whereas $\mathrm{G}(\mathrm{i})$ and $\mathrm{G}(\mathrm{s})$ target lipid rafts by default. Mol. Biol. Cell 12, 685-698.

Ostrom, R. S. (2002). New determinants of receptor-effector coupling: trafficking and compartmentation in membrane microdomains. Mol. Pharmacol. 61, 473-476.

Ostrom, R. S., Gregorian, C., Drenan, R. M., Xiang, Y., Regan, J. W., and Insel, P. A. (2001). Receptor number and caveolar co-localization determine receptor coupling efficiency to adenylyl cyclase. J. Biol. Chem. 276, 42063-42069.

Ostrom, R. S., Liu, X., Head, B. P., Gregorian, C., Seasholtz, T. M., and Insel, P. A. (2002). Localization of adenylyl cyclase isoforms and G protein-coupled receptors in vascular smooth muscle cells: expression in caveolin-rich and noncaveolin domains. Mol. Pharmacol. 62, 983-992.

Ostrom, R. S., Violin, J. D., Coleman, S., and Insel, P. A. (2000). Selective enhancement of beta-adrenergic receptor signaling by overexpression of adenylyl cyclase type 6 , colocalization of receptor and adenylyl cyclase in caveolae of cardiac myocytes. Mol. Pharmacol. 57, 1075-1079.

Palade, G. E. (1953). Fine structure of blood capillaries. J. Appl. Phys. 24, 1424

Parat, M. O., and Riggins, G. J. (2012). Caveolin-1, caveolae, and glioblastoma. Neuro. Oncol. 14, 679-688.

Park, D. S., Woodman, S. E., Schubert, W., Cohen, A. W., Frank, P. G., Chandra, M., et al. (2002). Caveolin-1/3 double-knockout mice are viable, but lack both muscle and non-muscle caveolae, and develop a severe cardiomyopathic phenotype. Am. J. Pathol. 160, 2207-2217.

Parton, R. G. (1994). Ultrastructural localization of gangliosides; GM1 
is concentrated in caveolae. J. Histochem. Cytochem. 42, 155-166.

Patel, H. H., Head, B. P., Petersen, H. N., Niesman, I. R., Huang, D., Gross, G. J., et al. (2006). Protection of adult rat cardiac myocytes from ischemic cell death: role of caveolar microdomains and delta-opioid receptors. Am. J. Physiol. Heart Circ. Physiol. 291, H344-H350.

Patel, H. H., Tsutsumi, Y. M., Head, B. P., Niesman, I. R., Jennings, M., Horikawa, Y., et al. (2007). Mechanisms of cardiac protection from ischemia/reperfusion injury: a role for caveolae and caveolin-1. FASEB J. 21, 1565-1574.

Peiro, S., Comella, J. X., Enrich, C., Martin-Zanca, D., and Rocamora, N. (2000). PC12 cells have caveolae that contain TrkA. Caveolaedisrupting drugs inhibit nerve growth factor-induced, but not epidermal growth factor-induced, MAPK phosphorylation. J. Biol. Chem. 275, 37846-37852.

Ramirez, C. M., Gonzalez, M., Diaz, M., Alonso, R., Ferrer, I., Santpere, G., et al. (2009). VDAC and ERalpha interaction in caveolae from human cortex is altered in Alzheimer's disease. Mol. Cell Neurosci. 42, 172-183.

Rapacciuolo, A., Suvarna, S., BarkiHarrington, L., Luttrell, L. M., Cong, M., Lefkowitz, R. J., et al. (2003). Protein kinase A and G protein-coupled receptor kinase phosphorylation mediates beta-1 adrenergic receptor endocytosis through different pathways. J. Biol. Chem. 278, 35403-35411.

Razani, B., Engelman, J. A., Wang, X. B., Schubert, W., Zhang, X. L., Marks, C. B., et al. (2001). Caveolin-1 null mice are viable but show evidence of hyperproliferative and vascular abnormalities. J. Biol. Chem. 276, 38121-38138.

Rohini, A., Agrawal, N., Koyani, C. N., and Singh, R. (2010). Molecular targets and regulators of cardiac hypertrophy. Pharmacol. Res. 61, 269-280.

Rose, B. A., Force, T., and Wang, Y. (2010). Mitogen-activated protein kinase signaling in the heart: angels versus demons in a heartbreaking tale. Physiol. Rev. 90, 1507-1546.

Rybin, V. O., Xu, X., Lisanti, M. P., and Steinberg, S. F. (2000). Differential targeting of beta -adrenergic receptor subtypes and adenylyl cyclase to cardiomyocyte caveolae. A mechanism to functionally regulate the cAMP signaling pathway. J. Biol. Chem. 275, 41447-41457.

Saugstad, J. A. (2010). MicroRNAs as effectors of brain function with roles in ischemia and injury, neuroprotection, and neurodegeneration. J. Cereb. Blood Flow Metab. 30, 1564-1576.

Schultz, J. J., Hsu, A. K., and Gross, G. J. (1997). Ischemic preconditioning and morphine-induced cardioprotection involve the delta (delta)opioid receptor in the intact rat heart. J. Mol. Cell Cardiol. 29, 2187-2195.

Scriven, D. R., Klimek, A., Lee, K. L., and Moore, E. D. (2002). The molecular architecture of calcium microdomains in rat cardiomyocytes. Ann. N.Y. Acad. Sci. 976, 488-499.

Segal, S. S., Brett, S. E., and Sessa, W. C. (1999). Codistribution of NOS and caveolin throughout peripheral vasculature and skeletal muscle of hamsters. Am. J. Physiol. 277, H1167-H1177.

Shin, T., Kim, H., Jin, J. K., Moon, C., Ahn, M., Tanuma, N., et al. (2005). Expression of caveolin-1, -2, and -3 in the spinal cords of Lewis rats with experimental autoimmune encephalomyelitis. J. Neuroimmunol. 165, 11-20.

Singer, S. J., and Nicolson, G. L. (1972). The fluid mosaic model of the structure of cell membranes. Science 175, 720-731.

Smart, E. J., Graf, G. A., McNiven, M. A., Sessa, W. C., Engelman, J. A., Scherer, P. E., et al. (1999). Caveolins, liquid-ordered domains, and signal transduction. Mol. Cell Biol. 19, 7289-7304.

Smart, E. J., Ying, Y., Donzell, W. C., and Anderson, R. G. (1996). A role for caveolin in transport of cholesterol from endoplasmic reticulum to plasma membrane. J. Biol. Chem. 271, 29427-29435.

Smythe, G. M., and Rando, T. A. (2006). Altered caveolin-3 expression disrupts $\mathrm{PI}(3)$ kinase signaling leading to death of cultured muscle cells. Exp. Cell Res. 312, 2816-2825.

Soni, A. (2011). Top 10 most costly conditions among men and women 2008, estimates for the U.S. civilian noninstitutionalized adult population, age 18 and older. Agency Healthc. Res. Qual. Stat. Brief 331, 1-5.

Steinberg, S. F., and Brunton, L. L. (2001). Compartmentation of $G$ protein-coupled signaling pathways in cardiac myocytes. Annu. Rev. Pharmacol. Toxicol. 41, 751-773.

Stern, C. M., and Mermelstein, P. G. (2010). Caveolin regulation of neuronal intracellular signaling. Cell. Mol. Life Sci. 67, 3785-3795.
Takayasu, Y., Takeuchi, K., Kumari, R., Bennett, M. V., Zukin, R. S., and Francesconi, A. (2010). Caveolin-1 knockout mice exhibit impaired induction of mGluR-dependent long-term depression at CA3-CA1 synapses. Proc. Natl. Acad. Sci. U.S.A. 107, 21778-21783.

Tang, Z., Scherer, P. E., Okamoto, T., Song, K., Chu, C., Kohtz, D. S., et al. (1996). Molecular cloning of caveolin-3, a novel member of the caveolin gene family expressed predominantly in muscle. J. Biol. Chem. 271, 2255-2261.

Tonkovic-Capin, M., Gross, G. J., Bosnjak, Z. J., Tweddell, J. S. Fitzpatrick, C. M., and Baker, J. E. (2002). Delayed cardioprotection by isoflurane: role of $\mathrm{K}(\mathrm{ATP})$ channels. Am. J. Physiol. Heart Circ. Physiol. 283, H61-H68.

Trajkovski, M., Hausser, J., Soutschek, J., Bhat, B., Akin, A., Zavolan, M., et al. (2011). MicroRNAs 103 and 107 regulate insulin sensitivity. Nature 474, 649-653.

Trushina, E., Du Charme, J., Parisi, J., and McMurray, C. T. (2006). Neurological abnormalities in caveolin-1 knock out mice. Behav. Brain Res. 172, 24-32.

Tsutsumi, Y. M., Horikawa, Y. T., Jennings, M. M., Kidd, M. W., Niesman, I. R., Yokoyama, U., et al. (2008). Cardiac-specific overexpression of caveolin-3 induces endogenous cardiac protection by mimicking ischemic preconditioning. Circulation 118, 1979-1988.

Tsutsumi, Y. M., Kawaraguchi, Y., Horikawa, Y. T., Niesman, I. R., Kidd, M. W., Chin-Lee, B., et al. (2010). Role of caveolin3 and glucose transporter-4 in isoflurane-induced delayed cardiac protection. Anesthesiology 112, 1136-1145.

Vatta, M., Ackerman, M. J., Ye, B., Makielski, J. C., Ughanze, E. E., Taylor, E. W., et al. (2006). Mutant caveolin-3 induces persistent late sodium current and is associated with long-QT syndrome. Circulation 114, 2104-2112.

Volonte, D., Galbiati, F., Pestell, R. G., and Lisanti, M. P. (2001). Cellular stress induces the tyrosine phosphorylation of caveolin-1 $(\operatorname{Tyr}(14))$ via activation of p38 mitogenactivated protein kinase and c-Src kinase. Evidence for caveolae, the actin cytoskeleton, and focal adhesions as mechanical sensors of osmotic stress. J. Biol. Chem. 276, 8094-8103.

Volonte, D., McTiernan, C. F., Drab, M., Kasper, M., and Galbiati, F.
(2008). Caveolin-1 and caveolin-3 form heterooligomeric complexes in atrial cardiac myocytes that are required for doxorubicininduced apoptosis. Am. J. Physiol. Heart Circ. Physiol. 294, H392-H401.

Waldenstrom, A., Genneback, N., Hellman, U., and Ronquist, G. (2012). Cardiomyocyte microvesicles contain DNA/RNA and convey biological messages to target cells. PLoS ONE 7:e34653. doi: 10.1371/journal.pone.0034653

Wang, X. L., Ye, D., Peterson, T. E., Cao, S., Shah, V. H., Katusic, Z. S., et al. (2005). Caveolae targeting and regulation of large conductance $\mathrm{Ca}(2+)$-activated $\mathrm{K}+$ channels in vascular endothelial cells. J. Biol. Chem. 280, 11656-11664.

Williams, T. M., and Lisanti, M. P. (2004). The caveolin proteins. Genome. Biol. 5, 214.

Willmann, R., Pun, S., Stallmach, L., Sadasivam, G., Santos, A. F. Caroni, P., et al. (2006). Cholesterol and lipid microdomains stabilize the postsynapse at the neuromuscular junction. EMBO J. 25, 4050-4060.

Zschocke, J., Manthey, D., Bayatti, N., van der Burg, B., Goodenough, S., and Behl, C. (2002). Estrogen receptor alpha-mediated silencing of caveolin gene expression in neuronal cells. J. Biol. Chem. 277, 38772-38780.

Conflict of Interest Statement: The authors declare that the research was conducted in the absence of any commercial or financial relationships that could be construed as a potential conflict of interest.

Received: 17 August 2012; accepted: 14 September 2012; published online: 05 October 2012.

Citation: Stary CM, Tsutsumi YM, Patel PM, Head BP, Patel HH and Roth DM (2012) Caveolins: targeting prosurvival signaling in the heart and brain. Front. Physio. 3:393. doi: 10.3389/fphys. 2012.00393

This article was submitted to Frontiers in Integrative Physiology, a specialty of Frontiers in Physiology.

Copyright (c) 2012 Stary, Tsutsumi, Patel, Head, Patel and Roth. This is an open-access article distributed under the terms of the Creative Commons Attribution License, which permits use, distribution and reproduction in other forums, provided the original authors and source are credited and subject to any copyright notices concerning any thirdparty graphics etc. 